\title{
ARQUIVO DA JUSTIÇA DO TRABALHO DE LONDRINA E SUA IMPORTÂNCIA NOS AMBIENTES DE MEMÓRIA.
}

\author{
Dra. Letícia Gorri Molina (UEL) \\ Giuliano Carlos de Araujo (TRT - 9 $9^{\text {a }}$ Região) \\ Regiana Pleis (Arquivologia - UEL)
}

\section{RESUMO}

A Sociedade Informacional traz novos paradigmas em relação às estruturas institucionais, às formas de relacionamento entre os indivíduos, aos novos meios de comunicação, assim como em relação à geração, registro, processamento e disseminação da informação e do conhecimento. Nesse cenário, evidencia-se o papel das instituições públicas como protagonistas de um ambiente que se caracteriza por uma extensa produção informacional que precisa ser organizada. A presente pesquisa tem como objetivo estudar e analisar a importância das memórias institucional e social do Arquivo da Justiça do Trabalho da cidade de Londrina (Tribunal Regional do Trabalho - $9^{\text {a }}$ Região) perante a sociedade. Para atender aos objetivos do estudo, utilizou-se da abordagem quali-quantitativa, caracterizando-se como pesquisa exploratória. Quanto aos procedimentos técnicos a pesquisa-ação, visto tratar-se de um tipo de pesquisa social, de fundamento empírico, concebida e realizada em associação a uma ação ou relativa à resolução de um problema de cunho coletivo. Como resultados preliminares verificaram-se: propor uma oficina de higienização e preservação de documentos; contratação de estagiários na área de Arquivologia para organização do acervo; auxílio na organização de exposições para a disseminaçãodo acervo da instituição, como forma de disseminação de sua memória, tanto para pesquisadores, quanto para o público em geral.

Palavras - chave: Memória Institucional, Memória Social, Justiça do Trabalho.

\section{INTRODUÇÃO}

A evolução dos tempos e a modernização tecnológica da sociedade atual trouxeram novas necessidades e exigências para a administração pública brasileira. Atualmente o cidadão não é mais mero espectador dos processos que envolvem os serviços prestados por um ente público, atua como ator, exercendo e exigindo que seus direitos sejam respeitados, entregues de forma ágil e com qualidade. Dentre estes direitos, estão o acesso à informação e o direito coletivo a preservação da memória, muitos característicos às unidades de Arquivo dos Poderes da União.

Os documentos dos arquivos públicos são patrimônio público, tanto no sentido administrativo quanto do ponto de vista histórico e cultural. Estes documentos possuem diversas áreas de interesses: o da instituição que o produziu, o cidadão que buscou exercer seus direitos no judiciário, e o interesse coletivo da preservação da memória.

De acordo com Schellenberg (2006), os Arquivos Públicos constituem um tipo de fonte de cultura entre muitos outros tipos como livros, manuscritos e tesouros de museus. Além da importância para a própria instituição e para o exercício dos direitos 


\section{SEMINÁRIO DE PESQUISA EM CIÊNCIAS HUMANAS - SEPECH \\ Humanidades, Estado e desafios didático-científicos \\ Londrina, 27 a 29 de julho de 2016}

daqueles que buscam a jurisdição, os documentos da Justiça do Trabalho têm papel fundamental em âmbito mais amplo, que é o do direito coletivo à memória.

Para Nora (1993, p.15 ), a memória verdadeira, transformada por sua passagem em história, dá lugar a uma memória arquivística, ou seja, "à constituição vertiginosa e gigantesca do estoque material daquilo que nos é impossível lembrar." Desta forma, o direito à memória significa não só criar condições para os pesquisadores realizarem suas pesquisas, mas também fornecer meios para a sociedade conhecer e reforçar sua identidade cultural.

Além disso, Belloto (2004, p.35) defende que as instituições de arquivo tem na "co-responsabilidade no processo de recuperação da informação, em benefício da divulgação científica, tecnológica, cultural e social, bem como do testemunho jurídico e histórico."

Este trabalho é parte do projeto de pesquisa: "A memória e a constituição de bases de conhecimento nos ambientes institucionais", registrado na Pró Reitoria de Pesquisa e Pós-graduação (PROPPG) da Universidade Estadual de Londrina, tendo como objetivo específico "Estudar os processos, fluxos e procedimentos para estruturação e implantação de modelos de memória nos ambientes organizacionais".

Desta forma, foi realizado um recorte para o presente trabalho, delimitando como objetivo estudar e analisar a importância das memórias institucional e social do Arquivo da Justiça do Trabalho da cidade de Londrina (Tribunal Regional do Trabalho - $9^{\text {a }}$ Região) perante a sociedade. Para tanto, utilizou-se do método de Pesquisa-ação, baseado em Thiollent (2004).

\section{ARQUIVO PÚBLICO}

De acordo com Schellenberg (2006), os arquivos como instituição provavelmente tiveram origem na antiga civilização grega, e eram conservados em templos. No templo, conservavam-se os tratados, leis, minutas da assembléia popular e demais documentos oficiais.

Para Côrtes (1996) o surgimento dos arquivos se deu por volta dos séculos IV e

$\mathrm{V}$ a.C. Estes surgiram como guardiões dos registros do Estado e para prestar apoio administrativo ao governo, quando devido à necessidade de se recorrer a documentos. A civilização grega passou a preocupar-se em guardar, junto à Corte de Justiça na Praça Pública de Atenas, leis, tratados, minutas de assembléia e documentos oficiais. Mais foi a partir da segunda guerra mundial, com a inclusão do direito à informação na Declaração dos Direitos Humanos de 1948, que transformou o acesso aos arquivos em direito democrático de todos os cidadãos e não mais uma reivindicação da pesquisa científica ou histórica.

Com a Revolução Francesa, a administração de arquivos é marcada pelo início de uma nova era, estabelecendo-se o quadro de uma administração de arquivos públicos de âmbito nacional. Os Arquivos Nacionais, fundados originalmente em 1789 como repartição dos arquivos parlamentares da Assembleia Nacional, passaram, pelo decreto de 24 de junho de 1794 (7 Messidor II), a constituir um estabelecimento central dos arquivos do Estado, ao qual foram subordinados os depósitos existentes nas províncias. O resultado foi que pela primeira vez uma administração orgânica de arquivos cobriu toda a rede de depósitos existentes de velhos materiais e de repartições públicas 


\section{SEMINÁRIO DE PESQUISA EM CIÊNCIAS HUMANAS - SEPECH \\ Humanidades, Estado e desafios didático-científicos \\ Londrina, 27 a 29 de julho de 2016}

criadoras de documentos (POSNER, 1940).

No Brasil, seguindo correntes e legislação, e em decorrência do processo de democratização dos arquivos, surgem os Arquivos Públicos. Segundo a Lei de Arquivos $\mathrm{n}^{\mathrm{o}} 8.159$ de 08 de janeiro de 1991 em seu Art. $7^{\circ}$, são "Os conjuntos de documentos produzidos e recebidos no exercício de suas atividades, por órgãos públicos de âmbito federal, estadual, do Distrito Federal e Municipal em decorrência de suas funções administrativas, legislativas e judiciárias.”(BRASIL, 1991).

Um Arquivo Público, independente da esfera de sua responsabilidade, deverá cumprir sua finalidade maior: efetuar a guarda dos documentos e torná-los disponíveis para consulta quando solicitados, seja pela própria instituição ou por terceiros. Neste sentido, Bellotto (2006, p. 227) afirma que os Arquivos Públicos existem "com a função precípua de recolher, custodiar, preservar e organizar fundos documentais originados na área governamental, transferindo-lhes informações de modo a servir ao administrador, ao cidadão e ao historiador".

\section{MEMÓRIA}

Para Jardim (1995) diversos termos tendem a ser associados à memória: resgate, preservação, conservação, registro, seleção etc. Crippa (2010, apud Lunardelli; Molina; Tonello, 2014) considera que a memória possibilita o resgate de algo relacionado ao passado, com o intuito de compará-lo com os dados do presente. Ela proporciona a preservação de determinadas informações essenciais para a experiência individual e o conhecimento de natureza científica, filosófica ou técnica.

As instituições custodiadoras de acervos como os Arquivos Públicos, são espaços de memória que possuem papel fundamental no desenvolvimento social, cultural e administrativo da sociedade. Estes espaços possuem como objetivos "[...] recolher, tratar, transferir, difundir informações." (BELLOTO, 2006, p. 35).

Neste contexto vale destacar que o "[...]conceito de memória institucional busca identificar elementos conceituais que atuam no processo de institucionalização das relações sociais. [...] processo que indica um conjunto de experiências que formam/conformam a identidade política e social dos indivíduos, bem como a imagem que têm de si mesmos e do outro, em suas relações com as instituições existentes na sociedade." Relações estas fundamentais para "[...] o processo de formação/aprendizagem social e política que conduz a cidadania." (THIESEN, 2013,p. 78 , grifo nosso).

No processo de institucionalização das relações sociais, um dos mecanismos ou instrumentos de invenção social, "a memória" deve ser priorizada, pois, é a memória e suas múltiplas visões o elemento conceitual e base de toda criação/institucionalização (THIESEN, 2013). Para Thiesen (2013, p.80) "A memória não é apenas a recuperação que se dá no presente de informações que tiveram existência no passado, quando então eram presentes." A memória que assim funciona é a memória-arquivo, apoiada em diversas superfícies de inscrição e que produz uma infinidade de documentos, da mesma forma que reproduz informação, conhecimento, dado e memória. Desta forma, "Para dar conta da memória-arquivo foram criadas, na história das grandes civilizações as instituições-memória que são denominados arquivos, bibliotecas e museus." (THIESEN, 2013, p. 81, grifo nosso) 


\section{SEMINÁRIO DE PESQUISA EM CIÊNCIAS HUMANAS - SEPECH \\ Humanidades, Estado e desafios didático-científicos \\ Londrina, 27 a 29 de julho de 2016}

Para Nora (1993, p.15), “[...] à constituição vertiginosa e gigantesca do estoque material daquilo que nos é impossível lembrar." memória verdadeira é transformada por sua passagem em história, que dá lugar a uma memória arquivística.

$\mathrm{Na}$ tipologia das instituições, as instituições-memória (arquivos, bibliotecas e museus) organizam a memória da memória e por isso são encarregados da representação destas memórias, e mesmo sendo instituições secundárias em relação aos saberes primariamente instituído, isso não as tornam menos relevantes no âmbito das instituições. "[...] o legado de invenções do homem - documentado e preservado pelas instituições-memória - tem uma forte função instituinte de novos saberes e novas criações." (THIESEN, 2013, p. 81-82)

Para Costa (1997, p.146), “[...] nós somos e fazemos as instituições. E a memória institucional é o reflexo dessa trajetória, não como mimesis, mas um cristal com suas múltiplas e infinitas facetas. É também uma memória histórica, efeito dos condicionamentos e das formações históricas".

Nesse contexto, as informações podem ser buscadas tanto interna quanto externamente às instituições. Além disso, a MI está em permanente elaboração e evolução, visto que é resultante da função do tempo, ou seja, a MI engloba a instituição como um todo, sendo formada com o passar do tempo. A autora também defende que os indivíduos é que fazem a memória das instituições, sendo ela o reflexo dessa trajetória social e histórica. Porém, Costa (1997) deixa claro, em sua pesquisa de doutorado, que o conceito de MI não foi definido de modo sistemático.

Nesse contexto, o que precisa ser analisado e avaliado, em relação à produção de informação, é o que realmente é relevante e importante para a organização guardar, visto que muito conteúdo é produzido diariamente, e nem todo conteúdo é relevante. Esse processo precisa ser pensado como um processo de estruturação da identidade institucional.

Para Le Goff (2003, p.422) “[...] o estudo da memória social é um dos meios fundamentais de abordar os problemas do tempo e da história, relativamente aos quais a memória está ora em retraimento, ora em transbordamento". Para o autor, a memória está sempre relacionada aos acontecimentos da história e, também, do tempo que rege a história.

Dessa forma, é que a memória - e suas várias possibilidades de guardar o passado - passa a ser um saber constituído de vários povos. Saber criado e socialmente construído. Quando se reconhece o papel dos sujeitos no processo cumulativo de transformação, a mensagem (cf. TEIXEIRA COELHO NETTO, 2003) socialmente transmitida ganha status de memória (SHIKIDA; MOURA, 2007).

Dodebei (2010), em seus estudos relativos à memória, verifica que “[...] é somente a partir do século XX que o mundo é visto como um espaço informacional e memorial, em que os aspectos materiais e imateriais dos objetos criados pelas sociedades entram em disputa". É nesse momento, que a produção cultural e social começa a ter valor de memória, resgatados e ligados à sociedade que a produz.

Dessa forma, Crippa (2010, p.81) considera que a memória permite o resgate de algo pertencente ao passado, comparando-os com os dados do presente, proporcionando a preservação de determinadas informações, essenciais para a experiência individual e o conhecimento de natureza científica, filosófica ou técnica. A memória é considerada o único instrumento através do qual, ideias e palavras podem ser reunidas, fugindo, assim, ao império do imediato: imprime as direções do tempo e 


\section{SEMINÁRIO DE PESQUISA EM CIÊNCIAS HUMANAS - SEPECH \\ Humanidades, Estado e desafios didático-científicos \\ Londrina, 27 a 29 de julho de 2016}

permite uma continuidade social. Sem ela, desapareceriam os elos sociais, assim como a própria noção de sociedade, as identidades individuais e coletivas, a possibilidade da construção do conhecimento, ou seja, pode ser considerada uma ferramenta para a construção de uma determinada sociedade, assim como de transmissão cultural.

Nesse contexto, a autora acima citada defende que as diversas formas de conhecimento existentes são fruto das formas de organização da memória de um conhecimento de uma época específica, que é ligada ao desenvolvimento pelo qual o pensamento científico passou e tem passado assim como referente aos objetivos das instituições públicas da época (CRIPPA, 2010, p.102).

Além disso, para Santos (2003, p.25-26), nós somos formados pela memória que temos; ela não é só pensamento, imaginação e construção social. Nossa memória é formada por uma determinada experiência de vida capaz de transformar outras experiências, quando em contato com resíduos deixados anteriormente. A memória vai além da mente humana, do corpo, do aparelho sensitivo e motor, do tempo físico; sendo objetivada em representações, rituais, textos e comemorações.

Podemos considerar que a memória está intimamente ligada ao futuro, pois é a partir do que temos internalizado como sujeitos cognoscentes, que nos estruturamos como indivíduos sociais e construímos nosso presente, e consequentemente, influímos em nosso futuro, isto é, não existe futuro sem passado.

A distinção passado/presente que aqui nos ocupa é a que existe na consciência coletiva, em especial na consciência social histórica. Mas torna-se necessário, antes de qualquer coisa, chamar a atenção para a pertinência desta posição e evocar o par passado/presente sob outras perspectivas, que ultrapassam as da memória coletiva e da história. De fato, a realidade da percepção e divisão do tempo em função de um antes e um depois não se limita, em nível individual/coletivo à oposição do presente/passado, é necessário acrescentar uma terceira dimensão, o futuro (LE GOFF, 2003, p.209).

Como defende Bergson (2010, p.47), um instante não substitui outro instante, pois desta forma, haveria somente o presente, não existindo um prolongamento do passado no presente, não existiria evolução, nem uma duração concreta. Duração esta que apresenta um progresso que é uma continuidade do passado, que o faz aumentar, conforme avança. Assim, pelo fato do passado crescer continuamente, também se preserva indefinidamente. Além disso, na visão de Bergson, a memória não serviria somente para classificar recordações em uma gaveta, nem de inscrevê-las em um registro. Esta seria uma percepção muito simplista para um mecanismo tão complexo quanto ela é.

\section{ARQUIVO DA JUSTIÇA DO TRABALHO DE LONDRINA}

Localizado na rua Pio XII, no centro da cidade, o arquivo do Judiciário Trabalhista da cidade de Londrina-PR funcionou, até o ano de 2009, em um imovél sem estrutura adequada para o desenvolvimento das funções de arquivo. O prédio não possuia ventilação, as instalações elétricas eram inadequadas, sofria com ação de roedores, e não havia servidores específicos e treinados para a gestão da documentação existente no local.

Os documentos de arquivo não eram acondicionados em caixas, apenas alocados em ordem numérica do processo em estantes de madeira, ficando expostos a 


\section{SEMINÁRIO DE PESQUISA EM CIÊNCIAS HUMANAS - SEPECH \\ Humanidades, Estado e desafios didático-científicos \\ Londrina, 27 a 29 de julho de 2016}

poeira, roedores e umidade. Como consequência, a organização da documentação e busca para disponibilização aos usuários tornava-se confusa e morosa, dado as condições de acondicionamento e guarda dos processos.

Em 2010, face a solicitação encaminhada a administração do Tribunal Regional do Trabalho (TRT) - $9^{a}$ região, depois de meses de obras e reformas no novo Fórum Trabalhista da cidade de Londrina, localizado na Avenida do café, $n^{\circ}$ 600, a nova unidade de Arquivo foi instalada. Neste novo local, várias correções foram executadas, proporcionando condições adequadas aos servidores agora lotados especificamente para as rotinas do Arquivo desempenhar os serviços inerente a um arquivo público.

Com a nova unidade instalada, uma área específica foi destinada para $\mathrm{o}$ atendimento do cidadão que busca informações contida nos processos arquivados, oferecendo conforto ao usuário, rapidez no atendimento e segurança nas informações prestadas sobre os documentos arquivados. Neste espaço, um servidor trabalha exclusivamente no atendimento, prestando todo suporte ao usuário quanto as informações necessárias para a retirada ou consulta de documentos de seu interesse.

Quanto ao acondicionamento dos documentos, o TRT investiu consideráveis recursos na aquisição de caixas de polipropileno, para manter os documentos do arquivo em caixas padronizadas e assegurar que estes documentos não estarão expostos a ação de agentes externos.

Com condições climáticas e de segurança adequadas, uma área de $2.000 \mathrm{~m}^{2}$ foi reservada ao depósito destinado a guarda de documentos, seguindo as orientações do Conarq sobre a estrutura fisica ideal para prédios destinados a receberem documentos de arquivo.

Para atender aos objetivos do estudo proposto, utilizou-se de uma abordagem quali-quantitativa, visto que a pesquisa quantitativa considera que tudo pode ser quantificável; se traduz em números as opiniões e informações para serem classificadas e analisadas. E pesquisa qualitativa, que de acordo com Neves (1996), não busca enumerar ou medir eventos e não emprega instrumentos estatísticos para análise dos dados coletados, mas sim, se desenvolve a partir de questões-chave, que são identificadas e formuladas pelo pesquisador, objetivando descobrir 'o quê?', 'por quê?' e 'como?'.

Esse tipo de pesquisa procura estudar os fenômenos que ocorrem no nosso cotidiano, segundo o ponto de vista dos participantes atuantes na situação foco do estudo. A partir desses elementos o pesquisador analisará e interpretará os fenômenos, diferente da pesquisa quantitativa que busca enumerar ou medir seus resultados através de instrumentos estatísticos.

Em relação aos objetivos propostos para a pesquisa, caracteriza-se como pesquisa exploratória, sendo aquela que busca constatar algo num organismo ou num fenômeno. Segundo Gil (1991) visa proporcionar maior familiaridade com o problema com vistas a torná-lo explícito ou a construir hipóteses. Envolve levantamento bibliográfico; entrevistas com pessoas que tiveram experiências práticas com $\mathrm{o}$ problema pesquisado; análise de exemplos que estimulem a compreensão.

Como método de pesquisa, utilizou-se da pesquisa-ação, visto que esta trata-se de um tipo de pesquisa social, de fundamento empírico, concebida e realizada em associação a uma ação ou relativa à resolução de um problema de cunho coletivo, sendo que os pesquisadores e participantes envolvidos com a situação ou problema, estão envolvidos de forma cooperativa ou participativa (THIOLLENT, 2004). Desta forma, 


\section{SEMINÁRIO DE PESQUISA EM CIÊNCIAS HUMANAS - SEPECH \\ Humanidades, Estado e desafios didático-científicos \\ Londrina, 27 a 29 de julho de 2016}

foram realizadas reuniões entre o grupo de pesquisa e o funcionário do arquivo, e visitas á instituição para observação e coleta de dados.

\section{RESULTADOS PRELIMINARES}

Os resultados são apresentados de acordo com dados coletados por meio de reuniões, visitas e observações realizadas na instituição.

Como o foco do projeto de pesquisa realizado na UEL é o estudo da memória em instituições, por meio de contatos realizados com o servidor do Arquivo da Justiça do Trabalho de Londrina com a coordenadora do projeto de pesquisa, foi apresentado o projeto de pesquisa que estava sendo realizado. Desta forma, foi agendada uma primeira reunião, com objetivo de apresentação do projeto de pesquisa e seus objetivos, além de identificar as necessidades do referido Arquivo.

Devido ao acervo da JT ter sido transferido de um imóvel em situação inadequada, para outro adequado e com possibilidades de efetuar ações de preservação e disseminação dos documentos que lá se encontram, percebeu-se que servidores da unidade tinham preocupação com o acervo e a preservação da memória desta instituição, assim como em divulgar o acervo ao público.

A instituição trabalha com dois tipos de acervo: o que guarda o documento provisório e o que guarda o documento definitivo/permanente. Estes documentos são processos oriundos de ações trabalhistas protocolizados no Judiciário Até o ano de 2011, eles eram somente no formato impresso, sendo que a partir daquele ano, foi instituído o Processo Jurídico Eletrônico (PJe), onde todo o trâmite dos processos seria realizado somente no formato eletrônico. Neste momento, o PJe está sendo implantado em todo o Poder Judiciário nacional, e como alguns processos em 2011 estavam em tramitação, estes tornaram-se híbridos, ou seja, parte dos processo continuou físico e parte digital.

O Arquivo do Judiciário Trabalhista de Londrina possui uma parte do acervo constituído de documentos antigos (décadas de 60,70,80) e que necessitam de cuidados específicos, e de não haver servidores com conhecimentos específicos em preservação e conservação documental, percebeu-se que os servidores necessitam de oficinas voltadas à higienização, restauro e preservação dos documentos existentes no acervo, ações que serão realizadas por um docente do departamento de Ciência da Informação, especializado na área de preservação e conservação de documentos.

Além disso, o Tribunal Regional do Trabalho do Paraná (TRT9 ${ }^{a}$ Região) não possui no seu quadro de servidores, a função de Arquivista, sendo que está sendo planejado um concurso para provimento desta vaga. Assim, por falta de servidores com conhecimentos específicos para tratamento do acervo documental, a instituição fez um convênio com a Universidade Estadual de Londrina para receber estagiários do curso de Arquivologia que farão um diagnóstico do acervo e a proposição de ações para o tratamento adequado do acervo.

Quanto à questão da memória, a instituição tem realizado, desde 2015, exposições temáticas do acervo, com intuito de divulgar e disseminar os documentos existentes no seu acervo. Desta forma, o grupo de pesquisa auxiliará na organização de exposições para a disseminação do acervo da instituição, como forma de disseminação de sua memória, tanto para pesquisadores, quanto para o público em geral. 


\section{SEMINÁRIO DE PESQUISA EM CIÊNCIAS HUMANAS - SEPECH \\ Humanidades, Estado e desafios didático-científicos \\ Londrina, 27 a 29 de julho de 2016}

Ainda em relação ao acesso ao acervo, está sendo discutida a elaboração de um projeto com objetivo de estruturar um espaço específico para receber pesquisadores, alunos e demais interessados em conhecer e realizar pesquisas no acervo.

Porém a realidade dos Arquivos Públicos brasileiros atualmente não permite esse fim, salvo raras exceções. Diversos motivos são apontados como fatores que impedem o cumprimento destas ações. Contudo um Arquivo Público, dado a sua importância para a própria instituição como também para a sociedade, deveria ser incluído no nível estratégico dos órgãos públicos brasileiros, e não ser considerado apenas com mais um setor ou departamento inócuo. Seus documentos são vitais para subsidiarem informações para a tomada de decisões da administração do órgão, e posteriormente, estes documentos, dada sua relevância no registro das ações do Estado, adquirem valor cultural.

\section{CONCLUSÕES}

Um Arquivo Público não pode ser analisado e estruturado apenas sob o ponto de vista legal, como uma unidade cumpridora de leis e regulamentos. Sua função maior, a de democratizar as informações contidas nos documentos sob sua guarda, deve ser planejada tanto quanto as demais funções do órgão a que pertence. Para tanto, faz-se necessário a inserção dos Arquivos dentro da estrutura administrativa do Estado; existência de programa de gestão de documentos e de recolhimento; formas de controle, organização, descrição e preservação do acervo; investimentos em espaço físico e recursos humanos; divulgação e estruturação em instrumentos de pesquisa para orientação do usuário e adequação aos recursos tecnológicos disponíveis aos usuários.

O trabalho de divulgação a respeito do valor memorial, cultural e social do acervo da JT, por meio das exposições e mostras, será uma forma de conscientizar a sociedade dos seus direitos de acesso e conhecimento do conteúdo do acervo depositado no local, visto que os Arquivos da Justiça do Trabalho têm uma rica produção documental que faz parte da memória de uma sociedade, mas também como documento de poder comprobatório.

Vale destacar, ainda, a importância do desenvolvimento de ações para conhecer melhor os usuários que utilizam os serviços da instituição como também ações para o desenvolvimento e atração de outros perfís de usuários, como o cidadão comum e o pesquisador universitário, pois conforme leciona Mason (1990 apud SMIT, 2003), o objetivo das instituições de custódia e dos profissionais que trabalham com informação centra-seno usuário, pois busca "disponibilizar a informação certa, da fonte certa, para ousuário certo, no prazo certo, numa forma considerada adequada para o uso e a umcusto justificado pelo uso" (MANSON 1990, p.125 apud SMIT, 2003, p.10).

Ao estimular e promover a preservação da memória da JT, ressalta-se que não podem ser considerados somente os aspectos jurídicos que envolvem um processo trabalhista. Soma-se a estes registros: toda uma evolução social; as relações estabelecidas nas sociedades; contextos econômicos que podem ser fontes de pesquisas de diversas áreas de estudo, como economia, contabilidade e ciências sociais. Nesse sentido, Schmidt (2010, p.7) defende que “Os processos são fontes de inegável valor histórico e que, além de seus aspectos jurídicos e dos documentos que contém - os quais podem se constituir em meio de prova para os cidadãos em outras demandas [...]." 


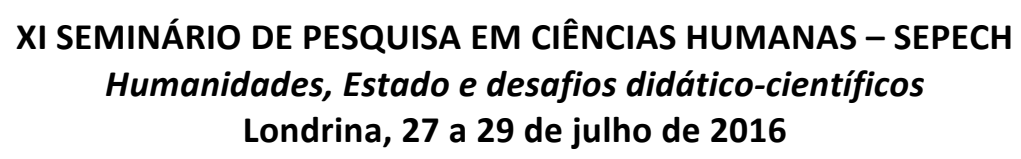

Como patrimônio, o acervo trabalhista é o registro de transição e superação de uma mentalidade autoritária para horizontes de emancipação e libertação; de conquistas no campo do Direito do Trabalho. Neste sentido, Prats (2004), afirma que "o patrimônio é uma construção social, não existindo naturalmente".

Tendo como foco a MI, e de acordo com Icléa Thiesen, que defende que seu conceito deve passar pelo processo de institucionalização das relações sociais, processo esse que se relaciona com experiências voltadas à formação da identidade política e social dos indivíduos, podemos considerar que o acervo da JT detém valor inestimável tanto como MI, quanto para a preservação da memória social da nação, sendo considerado como patrimônio cultural coletivo da sociedade brasileira, visto que registra a evolução dos direitos e deveres do trabalhador brasileiro, que liga o passado ao presente.

Assim, a preservação da memória da JT é um exercicio de cidadania, de crença nos valores sociais do trabalho, na superação do efêmero e no compromisso com a permanência dos valores que sustentam a república. É esse o norte que direciona a custodiado patrimônio documental jus trabalhista, pois se constitui num acervo que na verdade registra a formação de nossa identidade como nação.

\section{REFERÊNCIAS}

BELloto, H. Arquivos Permanentes: Tratamento Documental. São Paulo: T. A. Queiroz, 2004.

BERGSON, H. Memória e vida. 2.ed. São Paulo: WMF Martins Fontes, 2011. 184p. BRASIL. Lei $n^{\circ} 8.159 / 1991$ - Dispõe sobre a política nacional de arquivos públicos e privados e dá outras providências.

CÔRTES, M. R. P. A. Arquivo público e informação: acesso à informação nos arquivos públicos estaduais do Brasil. Belo Horizonte, 1996. Dissertação (Mestrado em Ciência da Informação) - Escola de Biblioteconomia da Universidade Federal de Minas Gerais.

COSTA, I. T. M. Memória institucional: a construção conceitual numa abordagem teórico-metodológico. Rio de Janeiro: UFRJ, 1997. Tese (Doutorado) - Programa de Pós-Graduação em Ciência da Informação - Universidade Federal do Rio de Janeiro (UFRJ), Rio de Janeiro, 1997

COUTURE, C.; ROUSSEAU, J. Y. Os Fundamentos da Disciplina Arquivística. Lisboa: Dom Quixote, 1998.

CRIPPA, G. Memória: geografias culturais entre história e ciência da informação. In: MURGUIA MARANON, E. I. (Org.). Memória: um lugar de diálogo para arquivos, bibliotecas e museus. São Carlos: Compacta, 2010. p.79-110 


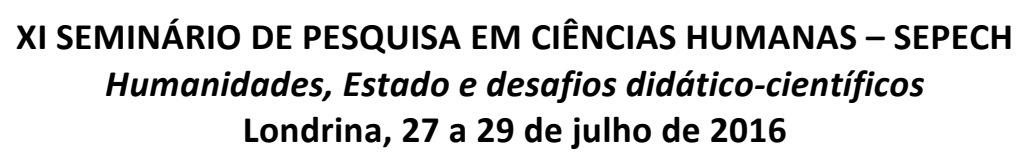

DODEBEI, V. L. D. L. de M. Informação, memória, conhecimento: convergência de campos conceituais. In: ENCONTRO NACIONAL DE PESQUISA EM CIÊNCIA DA INFORMAÇÃO, 10., 2010. ANAIS... Rio de Janeiro: UFRJ, 2010.

JARDIM, J. M. A invenção da memória nos arquivos públicos. Ciência da Informação, v. 25, n. 2, 1995.

LE GOFF, J. História e memória. 5. ed., Campinas, SP: Editora da Unicamp, 2003.

LUNARDELli, R. S. A.; MOLINA, L. G.; TONELlO, I. M. S. A constituição da memória dos procedimentos em saúde no contexto do prontuário eletrônico do paciente. Informação\&Informação, Londrina, v. 19, n. 3, p. 107 - 124, set./dez. 2014.

NORA, P. Entre memória e história: a problemática dos lugares. Projeto História: Revista do Programa de Estudos Pós-graduados em História e do Departamento de História PUC-SP. São Paulo: PUC-SP. N 10, 1993.

POSNER, E. Some aspects of archival development since the French Revolution. The American Archivist, jun. 1940, p. 159-172.

PRATS, L. Antropología y patrimonio. Barcelona: Ariel, 2004.

SANTOS, M. S. dos. Memória coletiva e teoria social. São Paulo: Annablume, 2003.

SCHELLENBERG, T. R. Arquivos modernos: princípios e técnicas. 6. ed. Rio de Janeiro: FGV, 2006.

SCHMIDT, B. B. Trabalho, justiça e direitos no Brasil: Pesquisa histórica e preservação das fontes. São Leopoldo: Oikos, 2010.

SHIKIDA, A. M. da SILVA; MOURA, M. A. Memória e redes sociais: informação e conhecimento em relatos orais. In: ENCONTRO NACIONAL DE PESQUISA EM CIÊNCIA DA INFORMAÇÃO, 8., 2007. ANAIS... Salvador: UFBA, 2007.

SMIT, J. W. Arquivologia/biblioteconomia: interfaces da Ciência da Informação. Informação\&Informação, Londrina, v. 8, n. 1, jun./dez. 2003.

THIESEN, Icléia. Memória Institucional. João Pessoa: UFPB, 2013. p. 153-198.

THIOLlENT, M. Metodologia da pesquisa-ação. 13.ed. São Paulo: Cortez, 2004. 